\title{
Structural characterization of calcium glycinate, magnesium glycinate and zinc glycinate
}

\author{
Li-Hui Yin*, Xu-Ping Liu ${ }^{\dagger}$, Lu-Yao Yiं, Jin Wang*, Ya-Jun Zhang* \\ and $\mathrm{Yu}$-Fei Feng* \\ *National Institutes for Food and Drug Control \\ Beijing 100050, P. R. China \\ ${ }^{\dagger}$ JiangXi Provincial Institute for Drug Control \\ Nanchang 330029, P. R. China \\ †sanyezao@yeah.net.
}

Received 20 March 2016

Accepted 31 August 2016

Published 14 October 2016

\begin{abstract}
Metal glycinate chelates are formed by glycine and metal compounds through chemical reactions. Calcium glycinate, magnesium glycinate and zinc glycinate are kinds of new-type and ideal nutrient supplements, which have satisfactory physico-chemical properties and bioactivities. They are important for prophylaxis and treat metal deficiency. The structural characterization shows that the metal ion is bonded to the amino and carboxyl group to form two five-membered rings. This paper mainly studies the structure characterization of the metal chelated glycinates by their solubility, infrared spectrum, thermal analysis, mass spectrometry, polycrystal diffraction, the metal contents and glycine contents of calcium glycinate, magnesium glycinate and zinc glycinate.
\end{abstract}

Keywords: Calcium glycinate; magnesium glycinate; zinc glycinate; structure characterization.

\section{Introduction}

Metal glycinate chelates are formed by glycine and metal compounds through chemical reactions, and are kinds of new-type and ideal nutrient supplements, which have satisfactory physico-chemical properties and bioactivities. They are the raw materials of great quantity of health care products having large market in China. But they are restricted because their structures not detected. Calcium glycinate, magnesium glycinate and zinc glycinate are formed by 2 to 1 chelate, and the metal ion is bonded to the amino and carboxyl group to form two five-membered rings (Fig. 1).

Understanding the structures of these species require a couple of analytical tools for their

\$Corresponding author.

This is an Open Access article published by World Scientific Publishing Company. It is distributed under the terms of the Creative Commons Attribution 4.0 (CC-BY) License. Further distribution of this work is permitted, provided the original work is properly cited. 


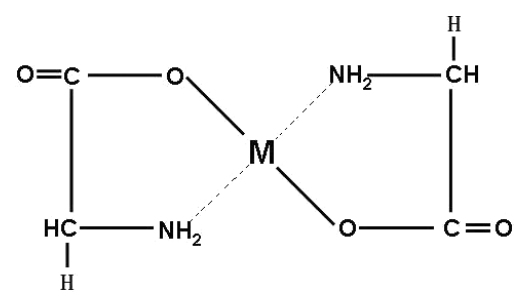

Fig. 1. The structure of chelated metal glycinate.

determination. Infrared spectroscopy and X-ray powder was applied to prove the reaction of iron and amino acid carboxyl group with one or more coordinate covalent bonds. ${ }^{1}$ If iron ion reacts with more than one carboxyl functional groups, it can generate to a $1: 2$ or 1:3 metal amino acid chelate molecules. 1:2 zinc glycinate was studied by X-ray diffraction to show the two chelating five-membered rings. ${ }^{2,3}$ The thermodynamic parameters for the formation of glycine complexes were detected. ${ }^{4}$ The difference between the ${ }^{13} \mathrm{C}$ NMR spectra of magnesium glycinate and glycine was reported. ${ }^{5}$ And a study was undertaken for the structures and fragmentation modes of the gasphase complexes of zinc attached to deprotonated amino acids in the gas phase by electrospray ionization. ${ }^{6}$ But the above detections cannot readily assess the structures of the chelated metal glycinate. Here, we present the structural characterization of calcium glycinate, magnesium glycinate and zinc glycinate by their solubility, infrared spectrum, thermal analysis, mass spectrometry, polycrystal diffraction, the metal content and glycine content of them.

\section{Materials and Methods}

\subsection{Samples}

Calcium glycinate (Fan mei (Beijing) Biological Products Co., Ltd., batch: 20071103C, 20071105C), magnesium glycinate glycine chelated magnesium (Fan mei (Beijing) Biological Products Co., Ltd., batch: 20071111M, 20071113M), zinc glycinate (Fan mei (Beijing) Biological Products Co., Ltd., batch: 20071107Z, 20071109Z).

\subsection{Solubility}

Metal oxide and glycine were the two raw materials which were used in the making of chelated metal glycinate. The solubilities of metal oxides and chelated metal glycinate were investigated at $25^{\circ} \mathrm{C}$. $200 \mathrm{mg}$ of metal oxides (calcium oxide, zinc oxide, magnesium oxide) and the batches of chelated metal glycinates respectively, were dissolved in $20 \mathrm{~mL}$ water, and then added $1 \mathrm{~mol} / \mathrm{L}$ hydrochloric acid in drops.

\subsection{Infrared spectrum}

All infrared spectrum of calcium glycinate, magnesium glycinate, and zinc glycinate were collected using a NEX us FT-IR spectrometer (Thermo Nicolet). ${ }^{7}$ The mid Fourier transform infrared spectrum recorded at $300 \mathrm{~K}$ in the range of 400 $4000 \mathrm{~cm}^{-1}$ following the $\mathrm{KBr}$ pellet technique. The functional groups were identified by the infrared spectrum.

\subsection{Mass spectrum}

High resolution mass spectrometry was used to determine the exact molecular weight of the compounds, ${ }^{8}$ which was an important parameter for chelate determination. The experimental setup with micro Q-TOF mass spectrometer (BRUKER), which includes a sample manipulator and a timeof-flight mass spectrometer (TOF-MS), which are housed in an ultra-high vacuum chamber (UHV) with a base pressure of about $10^{-9}$ Torr.

\subsection{Thermal analysis}

The thermal stabilities of GZC were studied by gravitation thermal analysis (GTA) using TGAQ500 TGA (U.S. TA company) between the temperatures $30^{\circ} \mathrm{C}$ and $1000^{\circ} \mathrm{C}$ at a heating rate of $15^{\circ} \mathrm{C} /$ $\mathrm{min}$ in nitrogen atmosphere, and differential thermal analysis (DTA) using DSC-Q200 (U.S. TA company) between the temperatures $40^{\circ} \mathrm{C}$ and $200^{\circ} \mathrm{C}$ at a heating rate of $10^{\circ} \mathrm{C} / \mathrm{min}$ in nitrogen atmosphere.

\subsection{Polycrystal diffraction}

X-ray absorption spectra were recorded at the institute of Materia Medica, ${ }^{9}$ Chinese Academy of Medical Sciences with the storage ring SPEAR operating at $3 \mathrm{GeV}$ and ring currents of $50 \pm 100 \mathrm{~mA}$. Selenium K-edge spectra were recorded on beamline 7-3 using a Si (220) double crystal monochromator with an upstream vertical aperture of $1 \mathrm{~mm}$. 
Selenium K-edge X-ray absorption spectra were measured as the Ka fluorescence excitation spectra using a Canberra 13-element germanium detector. The spectrum of hexagonal Se was collected simultaneously with each data set for energy calibration, with the first inflection of its absorption edge taken to be $12,658.0 \mathrm{eV}$. Sulfur K-edge spectra were recorded on beamline 6-2 with a $\mathrm{Si}$ (111) double crystal monochromator. Sulfur fluorescence was collected using a Stern-Heald-Lytle detector. Spectra were calibrated with reference to a solid sodium thiosulfate standard measured periodically during the run, the lowest energy K-edge absorption peak of which was $2469.2 \mathrm{eV}$. Samples were at room temperature for the sulfur measurements. Background subtraction and normalization were carried out according to established procedures.

\subsection{The contents analysis of metal ions}

Ion chromatography method was a high sensitivity, good accuracy method for the content analysis of metal ions. We used ion chromatographic methods to determine the metal ion contents of calcium glycinate and magnesium glycinate. ${ }^{10}$ But we could not determine zinc ion by the ion chromatography, so we used the inductively coupled plasma mass spectrometry (ICP-MS) to simultaneously determine the calcium, magnesium and zinc ion contents. ${ }^{11}$

The concentration of calcium and magnesium cations $\left(\mathrm{Ca}^{2+}, \mathrm{Mg}^{2+}\right)$ was determined with a Dionex ICS-3000 dual system consisting of a dual pump (DP) module, an eluent generator (EG) module, a detector chromatography (DC) module (single temperature zone configuration), and an autosampler (AS). The eluent contained $60 \mathrm{mmol} / \mathrm{L}$ sodium hydroxide $(\mathrm{NaOH})$, and the flow rate was $0.25 \mathrm{~mL} / \mathrm{min}$. Detection was the conductivity detector (CD) with integrated cell held at $35^{\circ} \mathrm{C}$. The conductivity suppressor was CSRS ULTRA II $(4 \mathrm{~mm})$, the guard column was Ionpac CG12A (cations) $(4 \times 50 \mathrm{~mm})$, and the column was Ionpac CS12A (cations) $(4 \times 250 \mathrm{~mm})$.

The concentrations of zinc cations $\left(\mathrm{Zn}^{2+}\right)$ was carried out on an ICP-MS (ICP-MS X-7, Thermo Scientific), which was operated with the plasma screen plus sensitivity enhancement option fitted, Xt interface cones, and with Peltier cooling of the spray chamber. A standard quartz nebulizer was used, together with a standard quartz impact bead spray chamber and standard single piece, $1.5 \mathrm{~mm}$ ID injector quartz torch. The instrument was operated using standard instrument operation. Plasma Lab software was applied to instrument control, data acquisition, and analysis. The instrumental and operating condition were optimized with the commentated tune solution. The operating parameters of ICP-MS instrument were as follows: RF power $1830 \mathrm{~W}$, coolant gas flow $14.3 \mathrm{~L} / \mathrm{min}$, auxiliary gas flow $0.95 \mathrm{~L} / \mathrm{min}$, nebulizer gas flow $0.87 \mathrm{~L} / \mathrm{min}$, pump rate $1.0 \mathrm{~mL} / \mathrm{min}$, and peak jumping data acquisition mode: dwell time $10 \mathrm{~s}$, duration time $60 \mathrm{~s}$, and three replicates per sample. The isotope of $\mathrm{SC}$ (IS) was monitored at $\mathrm{m} / \mathrm{z} 45$, full validation according to the FDA guidelines was, as far as applicable for ICP-MS, performed for the assay.

\subsection{The contents analysis of glycine}

Ion exchange chromatography was the common method for determination of amino acid. The methods were applied to analyze the glycinate contents of calcium glycinate, magnesium glycinate and zinc glycinate.

The concentration of glycine was determined with a Dionex ICS-3000 dual system consisting of a DP module, an EG module, a DC module (single temperature zone configuration), and an AS. The eluent contained $25 \% 250 \mathrm{mmol} / \mathrm{L}$ sodium hydroxide $(\mathrm{NaOH})$, and the flow rate was $0.25 \mathrm{~mL} / \mathrm{min}$. Detection was the amperometric detector, the guard column was Aminopac PA-10 Dionex (anions) $(4 \times 50 \mathrm{~mm})$, and the column was Aminopac PA-10 Dionex (anions) $(4 \times 250 \mathrm{~mm})$.

The ionic species was identified and quantified by interpolation on a proper calibration curve. All experiments were performed at room temperature and lasted approximately $10 \mathrm{~min}$ for each injected sample.

\section{Results}

\subsection{Results of solubility}

The chelated metal glycinate after oral administration was absorbed in the small intestine. We studied the solubility in the different $\mathrm{pH}$ solutions $(\mathrm{pH} 2-12)$. The solubilities of chelated metal glycinates were better than the corresponding metal oxides (calcium oxide, zinc oxide, magnesium oxide). The calcium 


\section{L.-H. Yin et al.}

glycinate, magnesium glycinate and zinc glycinate were also clear in the acidic solution.

\subsection{Results of infrared spectrum}

We studied the infrared spectrum of chelated metal glycinate and glycine. The formation of $\mathrm{NH}_{2}-\mathrm{M}$ bond and COO-M bond and the disappearance of $\mathrm{NH}_{3}$-glycine bond and $\mathrm{COO}-$ bond were the indications of the formation of five-membered ring structure of chelated metal glycinates.

There were $\mathrm{NH}_{3}$ and COO- groups in the molecules. In the infrared spectrum of chelated metal glycinate, $\mathrm{NH}_{3}$ peaks $\left(1111 \mathrm{~cm}^{-1}, 1131 \mathrm{~cm}^{-1}\right.$, $\left.2120 \mathrm{~cm}^{-1}\right)$ and COO-characteristic peaks $\left(502 \mathrm{~cm}^{-1}, 607 \mathrm{~cm}^{-1}, 697 \mathrm{~cm}^{-1}\right)$ all disappeared
(Note COO- and other base groups combined). The $\mathrm{NH}_{2}$ peaks $\left(3342 \mathrm{~cm}^{-1}, 3450 \mathrm{~cm}^{-1}\right)$ also inferred that the three chelated metal glycinates have generated $\mathrm{M}-\mathrm{NH}_{2}$ group and $\mathrm{COO}-\mathrm{M}$ groups (Fig. 2).

\subsection{Results of mass spectrum}

Calcium glycinate, magnesium glycinate and zinc glycinate were analyzed by high-resolution mass spectrometries. The results showed that all the three had the molecular ion peaks $([\mathrm{M}+\mathrm{Gly} 2+$ $\mathrm{H}] 1+$, M: metal ions, Gly: glycine) in the mass spectrum, which proved that molar ratio is $1: 2$ of $\mathrm{M}$ and glycines (Fig. 3).

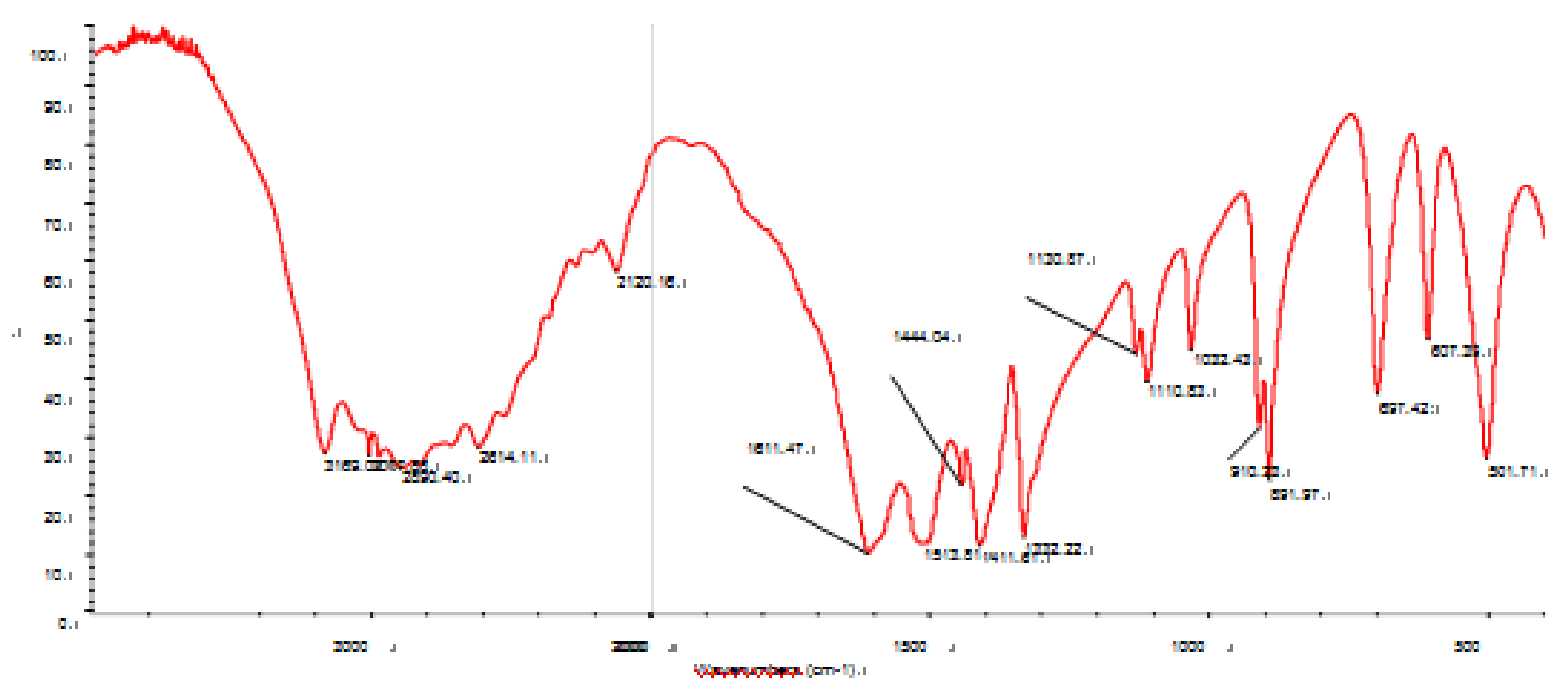

(a)

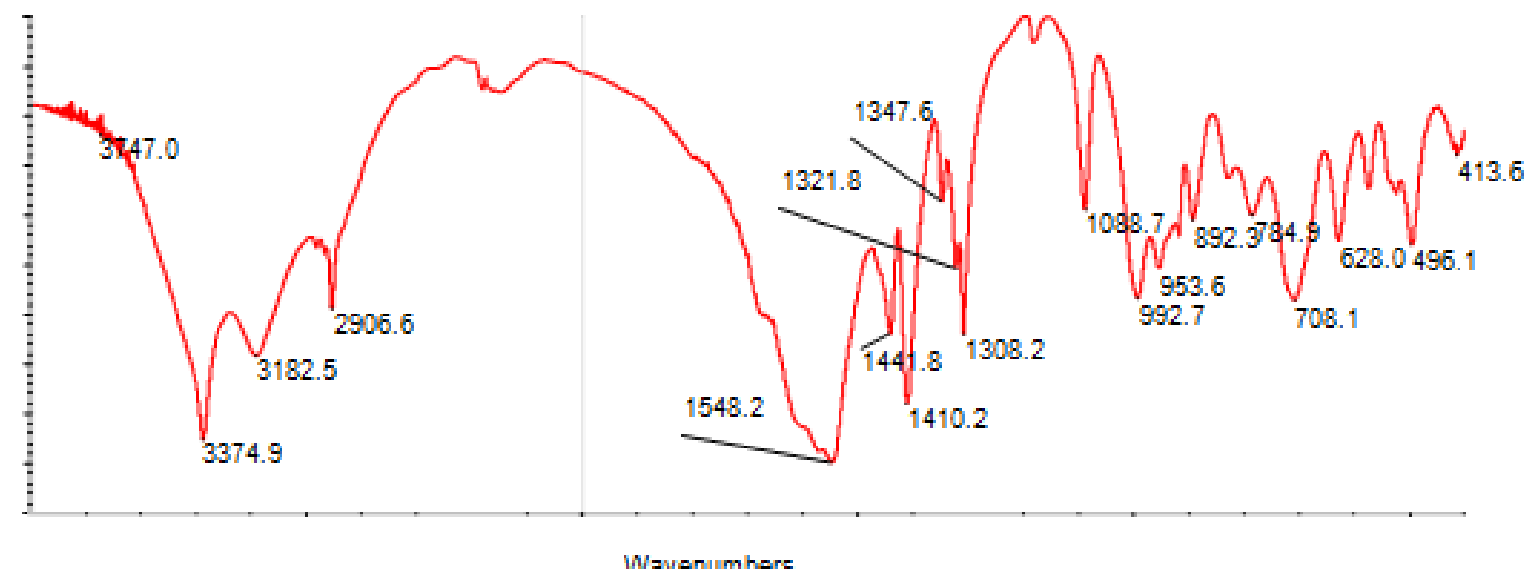

(b)

Fig. 2. The infrared spectrum of glycinate (a), calcium glycinate (b), magnesium glycinate (c), and zinc glycinate (d). 
Structural characterization of calcium glycinate, magnesium glycinate and zinc glycinate

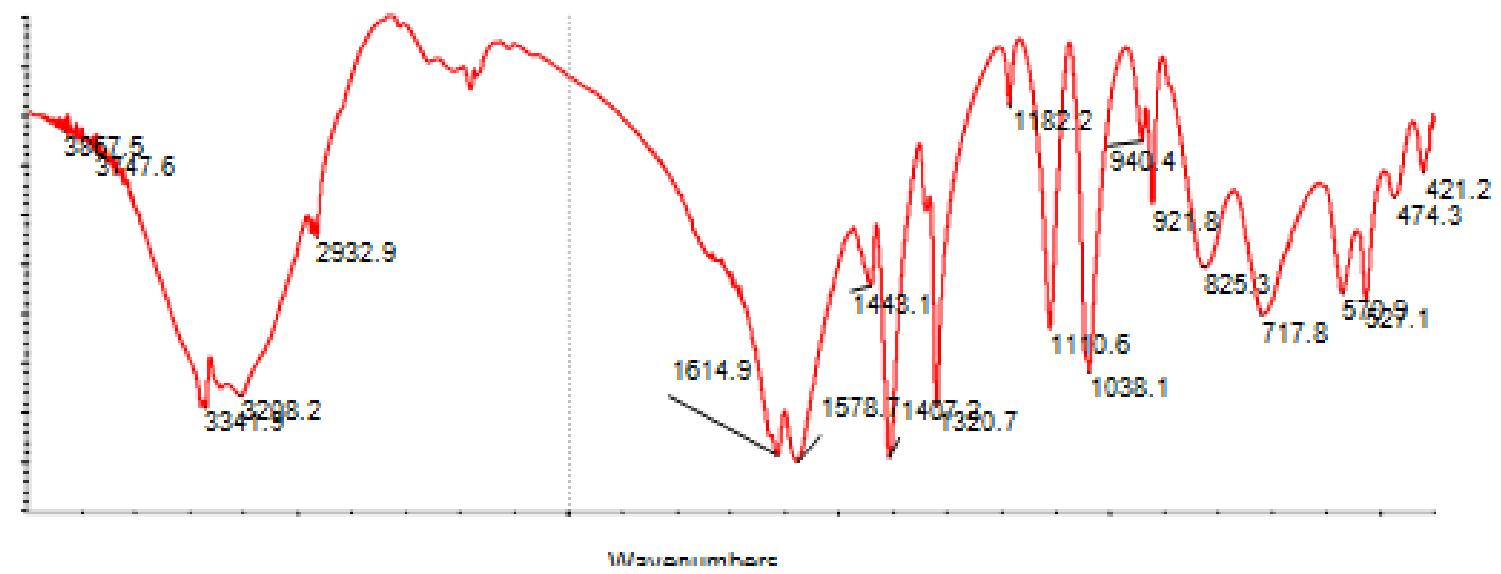

(c)

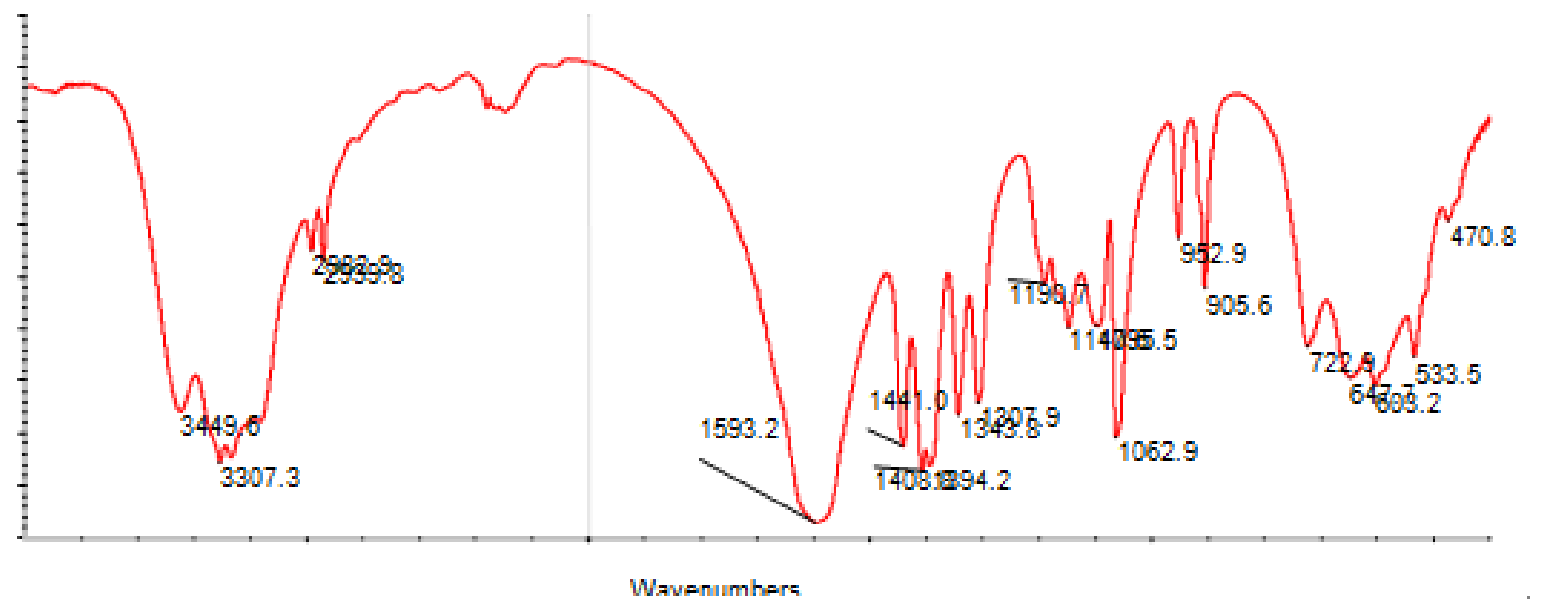

(d)

Fig. 2. (Continued)

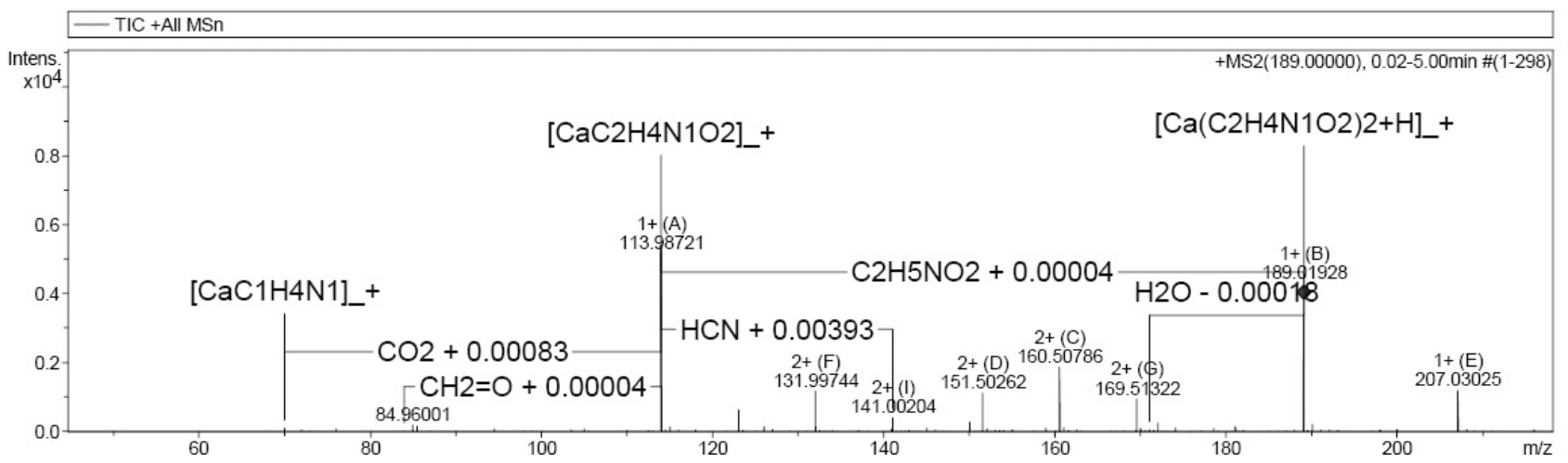

(a)

Fig. 3. The mass-mass spectra of calcium glycinate (a), the mass-mass spectra of magnesium glycinate (b), the mass-mass spectra of zinc glycinate $(\mathrm{c})$. 


\section{L.-H. Yin et al.}

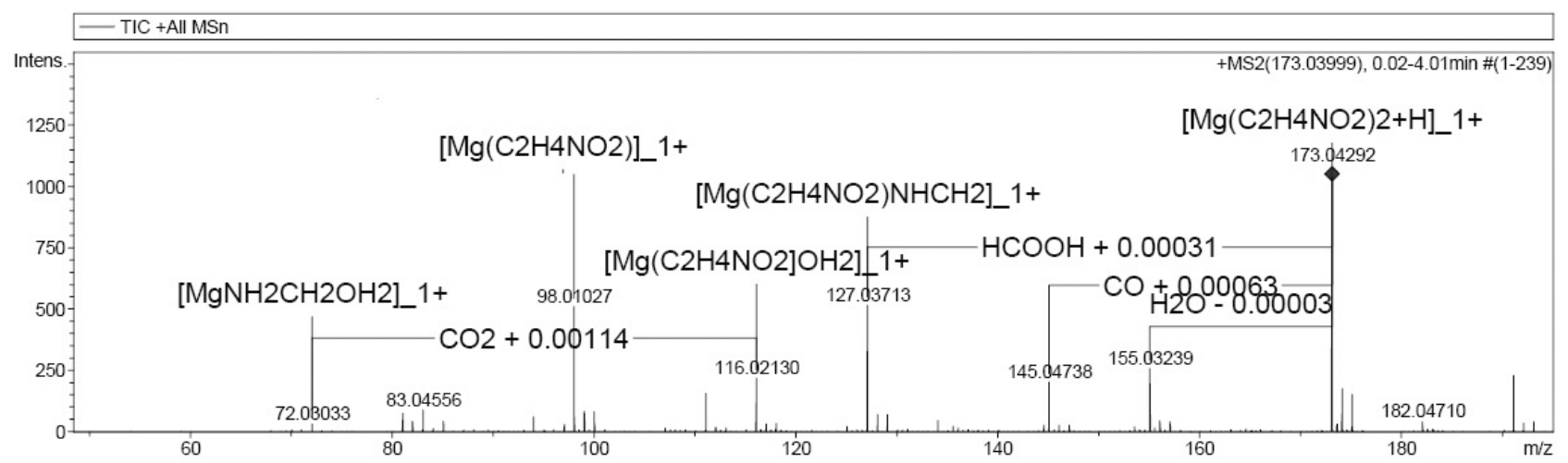

(b)

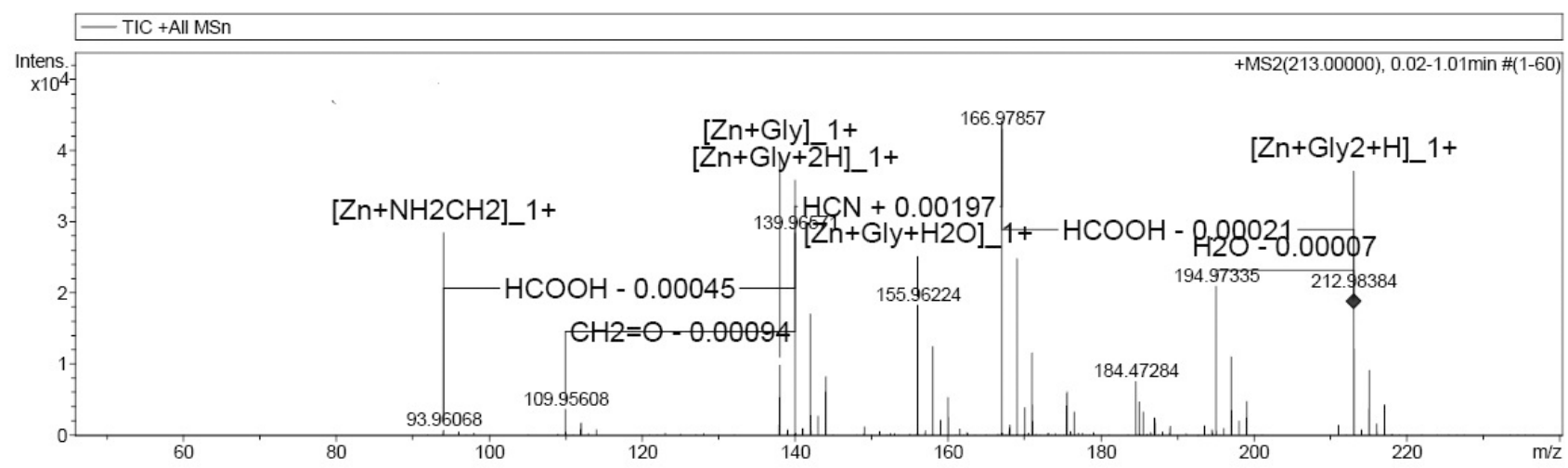

(c)

Fig. 3. (Continued)

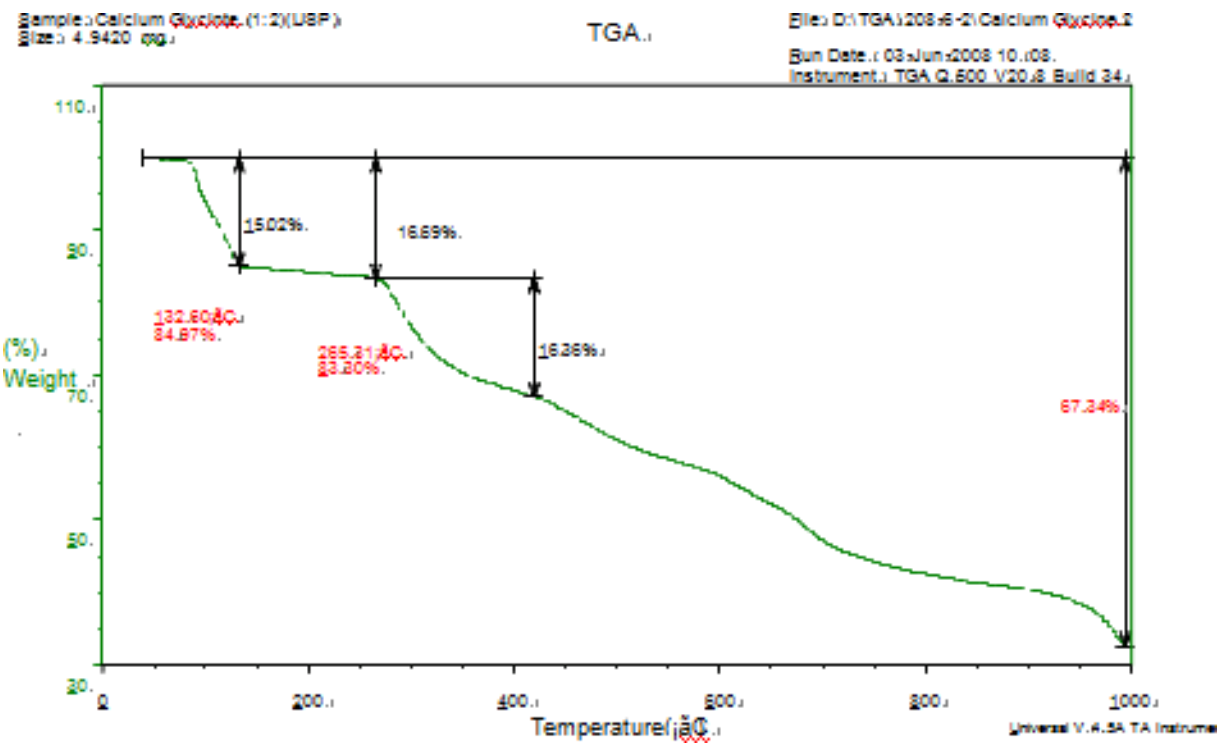

(a)

Fig. 4. The GTA of calcium glycinate (a), the DTA of calcium glycinate (b), the GTA of magnesium glycinate (c), the DTA of magnesium glycinate (d), the GTA of zinc glycinate (e), the DTA of zinc glycinate (f). 
Structural characterization of calcium glycinate, magnesium glycinate and zinc glycinate

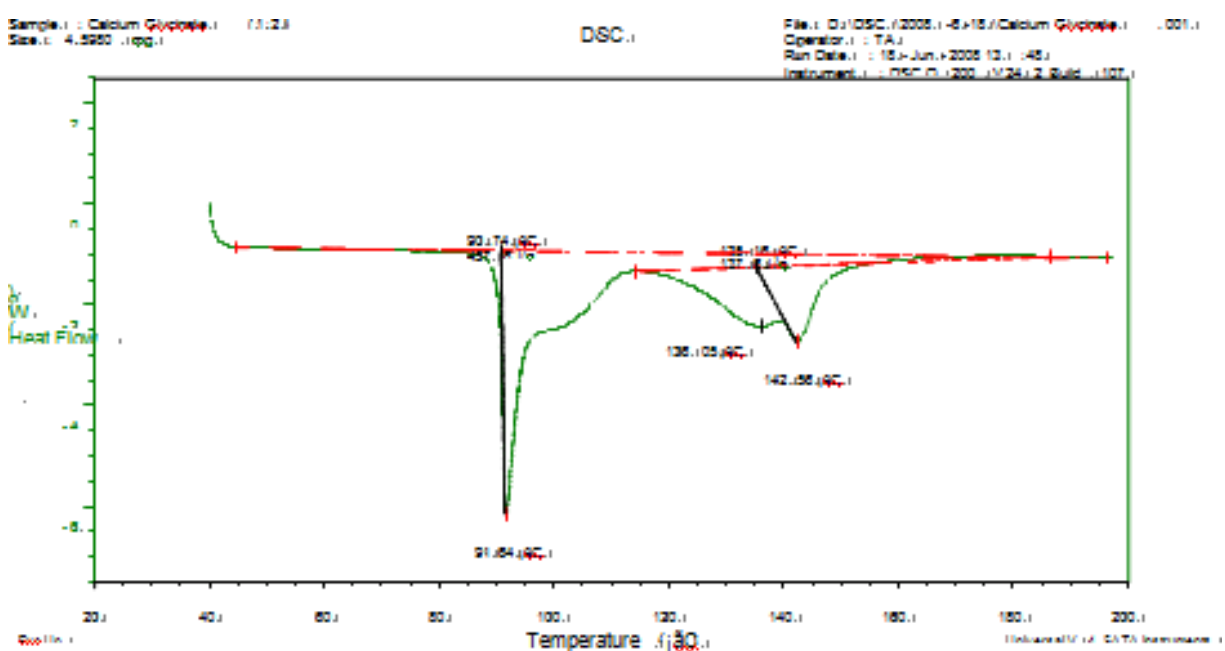

(b)

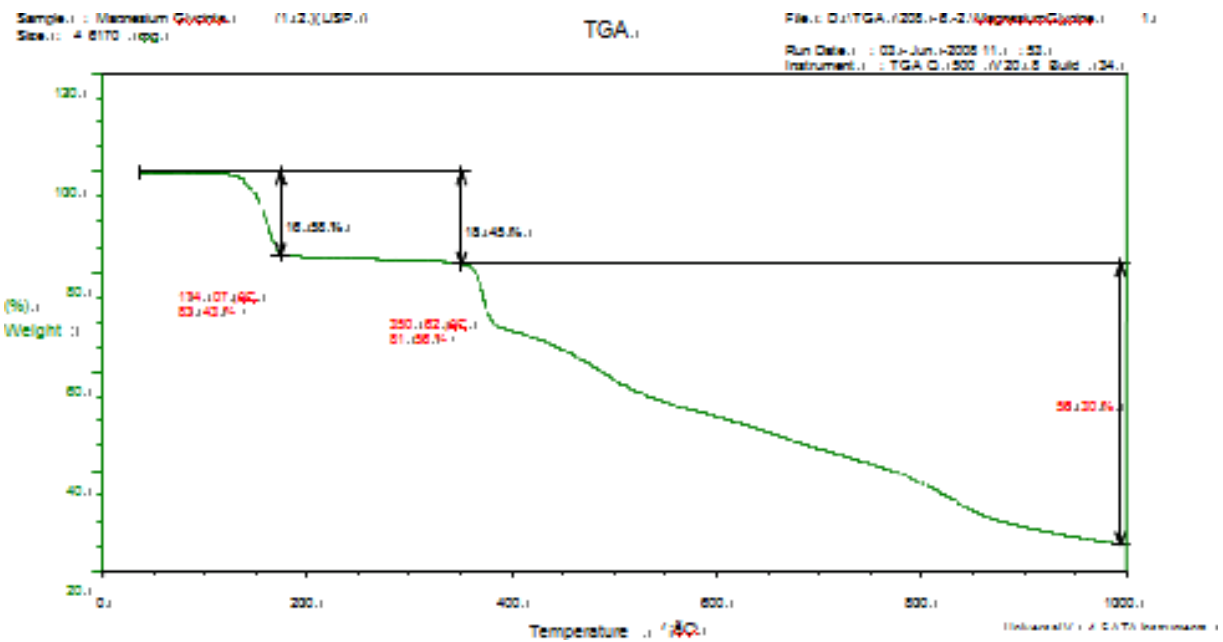

(c)

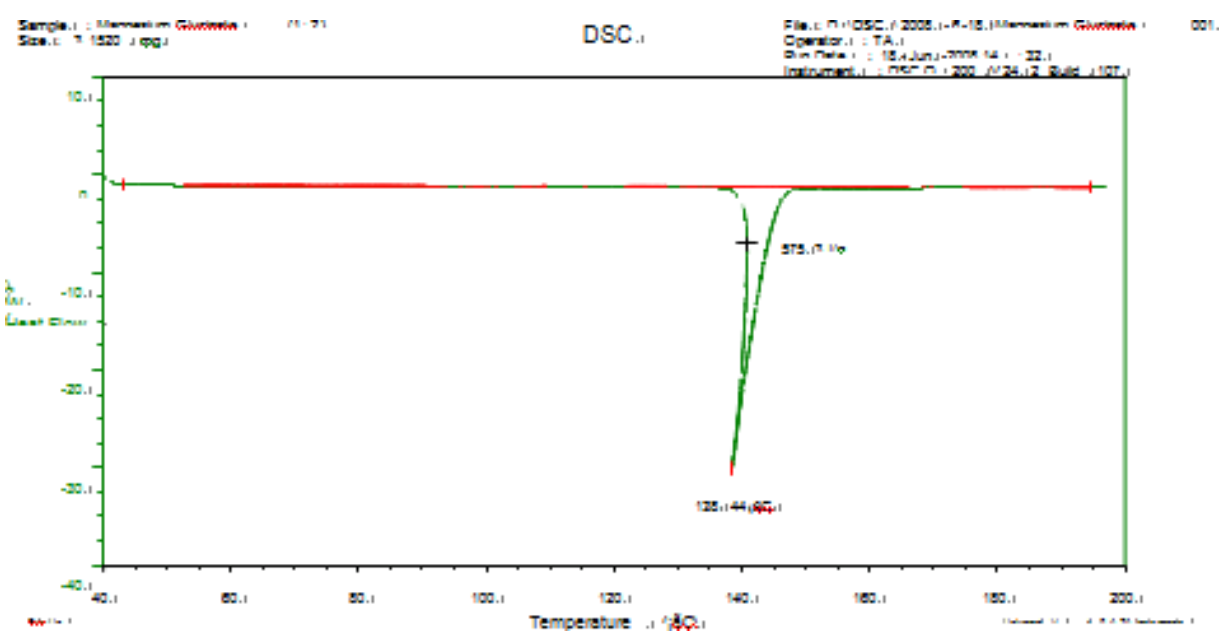

(d)

Fig. 4. (Continued) 


\section{L.-H. Yin et al.}

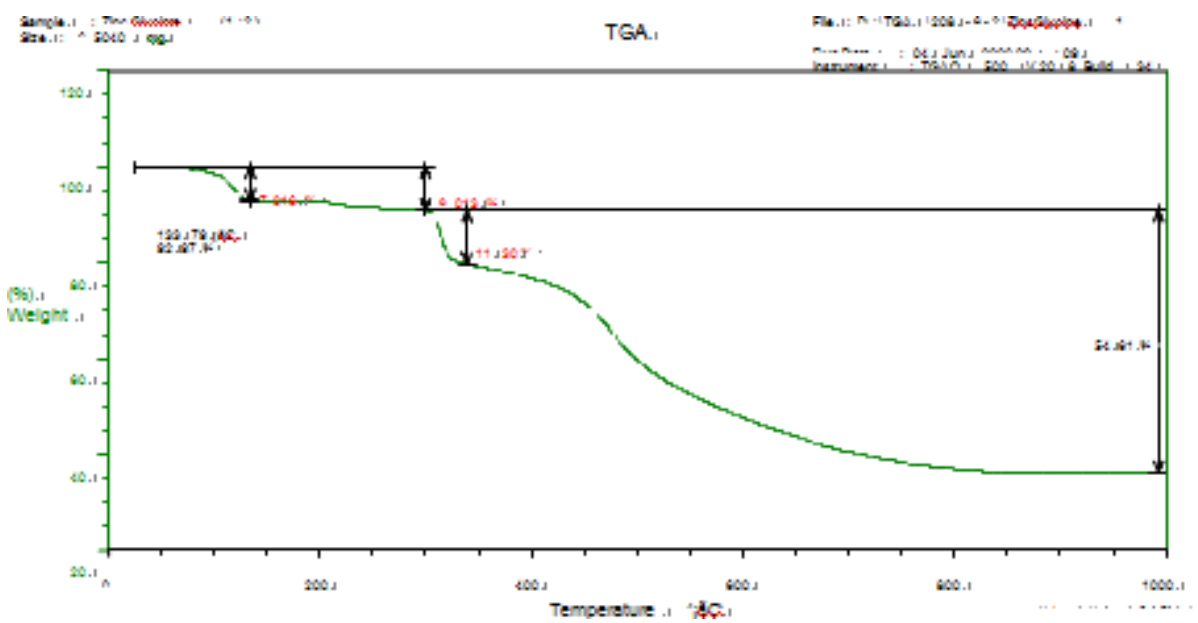

(e)

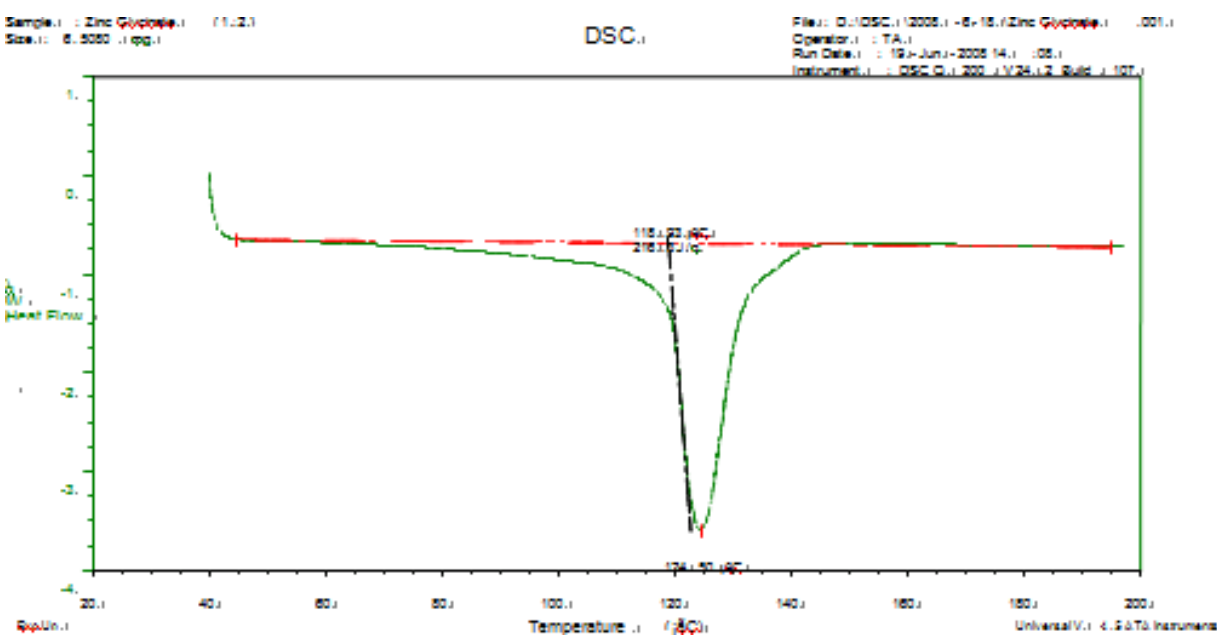

(f)

Fig. 4. (Continued)

Mass spectrometry proved that $\mathrm{M}-\mathrm{O}$ ionic bond and $\mathrm{M}$...N coordinate covalent bond exists in molecules. They confirmed the structures of calcium glycinate, magnesium glycinate and zinc glycinate, the structures were shown in Fig. 1.

\subsection{Results of thermal analysis}

We studied calcium glycinate, magnesium glycinate and zinc glycinate for the GTA and differential scanning analysis. The scanning prints showed the

Table 1. Results of thermal analysis.

\begin{tabular}{lccc}
\hline & Calcium glycinate & Magnesium glycinate & Zinc glycinate \\
\hline The temperature range & $90-180^{\circ} \mathrm{C}$ & $130-180^{\circ} \mathrm{C}$ & $60-180^{\circ} \mathrm{C}$ \\
The weight loss range & $15.02^{\circ} \mathrm{C}-16.69 \%$ & $16.58^{\circ} \mathrm{C}-18.45 \%$ & $7.02^{\circ} \mathrm{C}-9.01 \%$ \\
The supposed molecular formula & $\mathrm{Gly}_{2} \mathrm{Ca} .2 \mathrm{H}_{2} \mathrm{O}$ & $\mathrm{Gly}_{2} \mathrm{Mg}_{2} . \mathrm{H}_{2} \mathrm{O}$ & $\mathrm{Gly}_{2} \mathrm{Zn} . \mathrm{H}_{2} \mathrm{O}$ \\
The theoretical value of water content & $16.06 \%$ & $17.27 \%$ & $7.78 \%$ \\
Conclusion & Contained two molecular & Contained two molecular & Contained one molecular \\
& crystal water & crystal water & crystal water \\
\hline
\end{tabular}


Table 2. The contents of calcium ion in calcium glycinate.

\begin{tabular}{lc}
\hline Batch & Calcium glycinate (\%) \\
\hline $20071103 \mathrm{C}$ & 14.2 \\
$20071105 \mathrm{C}$ & 14.9 \\
\hline
\end{tabular}

Table 3. The contents of magnesium ion in magnesium glycinate.

\begin{tabular}{lc}
\hline Batch & Magnesium glycinate (\%) \\
\hline $20071111 \mathrm{M}$ & 9.8 \\
$20071113 \mathrm{M}$ & 10.1 \\
\hline
\end{tabular}

GTA and DTA in Fig. 4. The results were summarized in Table 1.

\subsection{Results of polycrystal diffraction}

Polycrystal diffraction methods were used to study glycine and three chelated metal glycinates.

Table 4. The contents of zinc ion in zinc glycinate.

\begin{tabular}{lc}
\hline Batch & Zinc glycinate (\%) \\
\hline $20071107 Z$ & 32.7 \\
$20071109 Z$ & 28.3 \\
\hline
\end{tabular}

Table 5. The glycine contents of the three metal chelated glycinates.

\begin{tabular}{lcc}
\hline Sample & Batch & The glycine content (\%) \\
\hline Calcium glycinate & $20071103 \mathrm{C}$ & 67.0 \\
& $20071105 \mathrm{C}$ & 65.2 \\
Zinc glycinate & $20071107 \mathrm{Z}$ & 66.9 \\
& $20071109 \mathrm{Z}$ & 66.6 \\
Magnesium glycinate & $20071111 \mathrm{M}$ & 71.0 \\
& $20071113 \mathrm{M}$ & 71.6 \\
\hline
\end{tabular}

The results showed that: the powders of glycine and three chelated metal glycinates were quite different. It proved that chemical reaction happened during the formation of chelated compounds. ${ }^{12}$

\subsection{Results of metal ion contents analysis}

The results were shown in Tables 2-4.

\subsection{Results of the contents analysis of glycine}

Ion exchange chromatography was commonly used for the determination of amino acid, in which we utilized it to analyze the glycine content of the three chelated metal glycinates. It could be used for almost any kind of charged molecule including large proteins, small nucleotides and amino acids. ${ }^{10}$ The method was used to determine the glycine contents of the three metal chelated glycinates, the glycine contents were shown in Table 5 .

\section{Discussion}

The summary of the results of solubility, infrared spectroscopy, thermal analysis, mass spectrometry, polycrystal diffraction, metal content and glycine content are shown in Table 6.

With this result, we can determine that all the three chelated metal glycinates have five-membered ring structure (Fig. 1). Calcium glycinate and magnesium glycinate contained two crystalline water molecules and zinc glycinate contained one crystalline water molecule.

Table 6. Summary of the comprehensive analysis results.

\begin{tabular}{|c|c|c|c|c|c|c|c|}
\hline Molecular formula & Mol.wt. & $\begin{array}{l}\text { The theoretical } \\
\text { value of water } \\
\text { content }(\%)\end{array}$ & $\begin{array}{c}\text { The actual } \\
\text { value of } \\
\text { water } \\
\text { content }(\%)\end{array}$ & $\begin{array}{c}\text { The theoretical } \\
\text { value of glycine } \\
\text { content }(\%)\end{array}$ & $\begin{array}{l}\text { The actual } \\
\text { value of } \\
\text { glycine } \\
\text { content }(\%)\end{array}$ & $\begin{array}{l}\text { The theoretical } \\
\text { value of metal } \\
\text { ion content }(\%)\end{array}$ & $\begin{array}{c}\text { The actual } \\
\text { value of metal } \\
\text { ion content }(\%)\end{array}$ \\
\hline$\left(\mathrm{NH}_{2} \mathrm{CH}_{2} \mathrm{COO}\right)_{2} \mathrm{Zn} \cdot \mathrm{H}_{2} \mathrm{O}$ & 231.51 & 7.78 & 8.28 & 63.98 & 69.4 & 28.25 & 30.50 \\
\hline$\left(\mathrm{NH}_{2} \mathrm{CH}_{2} \mathrm{COO}\right)_{2} \mathrm{Mg} \cdot 2 \mathrm{H}_{2} \mathrm{O}$ & 208.43 & 17.27 & 16.95 & 71.06 & 71.1 & 11.66 & 10.00 \\
\hline$\left(\mathrm{NH}_{2} \mathrm{CH}_{2} \mathrm{COO}\right)_{2} \mathrm{Ca} \cdot 2 \mathrm{H}_{2} \mathrm{O}$ & 224.20 & 16.06 & 17.46 & 66.07 & 63.0 & 17.88 & 14.60 \\
\hline
\end{tabular}




\section{References}

1. T. Fujita, T. Sato, M. Uchiyama, H. Hoshida, K. Kawabe, J. Yoshiro, T. Wakabayashi, "Binding of iron ions with soybean protein," Hygiene Chem. 28, 106-110 (1982).

2. H. Jennifer, E. Clayton, D. A. Stephen, US Patent. 714-737 (2011).

3. J. M. Newman, C. A. Bear, T. W. Hambley, H. C. Freeman, "Structure of bis (glycinato) zinc (II) monohydrate, a five-coordinate zinc (II) complex," Acta Crystallogr. C. 46, 44-48 (1990).

4. C. Agatino, D. R. Alessandro, D. S. Concetta, G. Antonio, P. Grazia, R. Carmelo, S. Silvio, "Thermodynamic parameters for the formation of glycine complexes with magnesium (II), calcium (II), lead (II), manganese (II), cobalt (II), nickel (II), zinc (II) and cadmium (II) at different temperatures and ionic strength, with particular reference to natural fluid," Thermochim. Acta 255, 109-141 (1995).

5. J. Tian, Y. Yin, "Novel phenomena in the 13C NMR spectra of amino acids," Amino Acids 26, 175-181 (2004).

6. O. R. Franc, H. Yannik, O. Gilles, "Structures and fragmentations of zinc (II) complexes of amino acids in the gas phase. III. Rearrangement versus desolvation in the electrospray formation of the glycinezinc complex," Int. J. Mass Spectrom. 206, 45-52 (2001).
7. C. Li, J. Dou, J. Cao, "A novel chelating organosilicone resin bearing long chain imidazolyl ligands: Preparation, characterization, and adsorption properties," J. Organometal. Chem. 727(5), 37-43 (2013).

8. L. Tastet, D. Schaumlöffel, A. Yiannikouris, "Insight in the transport behavior of copper glycinate complexes through the porcine gastrointestinal membrane using an Ussing chamber assisted by mass spectrometry analysis," J. Trace Elem. Med. Biol. 24(2), 124-129 (2010).

9. G. Predieri, D. Beltrami, R. Pattacini, "Structural studies in solution and in the solid state on the zinc chelate of 2-hydroxy-(4-methylthio)butanoic acid, an effective mineral supplement in animal feeding," Inorgan. Chim. Acta 362(4), 1115-1121 (2009).

10. S. Corrado, "Recent developments in ion chromatography," J. Chromatogr. A 956, 3-13 (2002).

11. J. Szpunar, J. Bettmer, M. Robert, H. Chassaigne, K. Cammann, R. Lobinski, O. F. X. Donard, "Validation of the determination of copper and zinc in blood plasma and urine by ICP MS with crossflow and direct injection nebulization," Talanta 44, 1389-1996 (1997).

12. M. Graf, K. Sünkel, "Cyclometalated rhodium(III) and iridium(III) complexes containing amino acids as N,O-chelates," Inorgan. Chim. Acta 371(1), 42-46 (2011). 